\title{
Helsinki Declaration implementation after 6 years: evaluation of current status in hospitals in Catalonia
}

\author{
Alarcón A, Moret E, Canet J. \\ University Hospital Germans Trias i Pujol, Dept . of Anaesthesiology \& Intensive Care, Badalona, Spain
}

\section{Introduction:}

Patient safety is an essential component of risk management, clinical management and quality improvement. According to a systematic review published in 2008, the overall incidence in hospitals of adverse events was $9.2 \%$, of these, $43.5 \%$ were preventable if adequate safety measures had been applied (1).

The Helsinki Declaration (HD) on Patient safety in Anaesthesiology was signed in June 2010 in Europe in order to improve patient safety in preoperative anaesthesia care (2).

\section{Objective:}

The aim of this study was to assess the current state of accomplishment among hospitals in Catalonia, which cover a population of 7.5 million people.

\section{Materials and Methods:}

An on-line survey was sent by email to the heads of departments of all hospitals in Catalonia. The survey analyzed the accomplishment of all recommendations outlined in the Helsinki declaration (2):

\section{- Patient monitoring}

- Protocols

- WHO checklist

- Safety report

- Morbidity and mortality conferences

- Critical incident reporting

\section{- Sedation}

Data are presented as absolute numbers and/or percentages.

\section{Results and Discussion:}

A total of 29 completed questionnaires were collected out of 40 Anaesthesiology Departments (response rate of $72.5 \%$ ). Of which 24 public and 5 private institutions; 11 universitary hospitals; 17 tertiary hospitals and 9 secondary hospitals.

Fig. 1

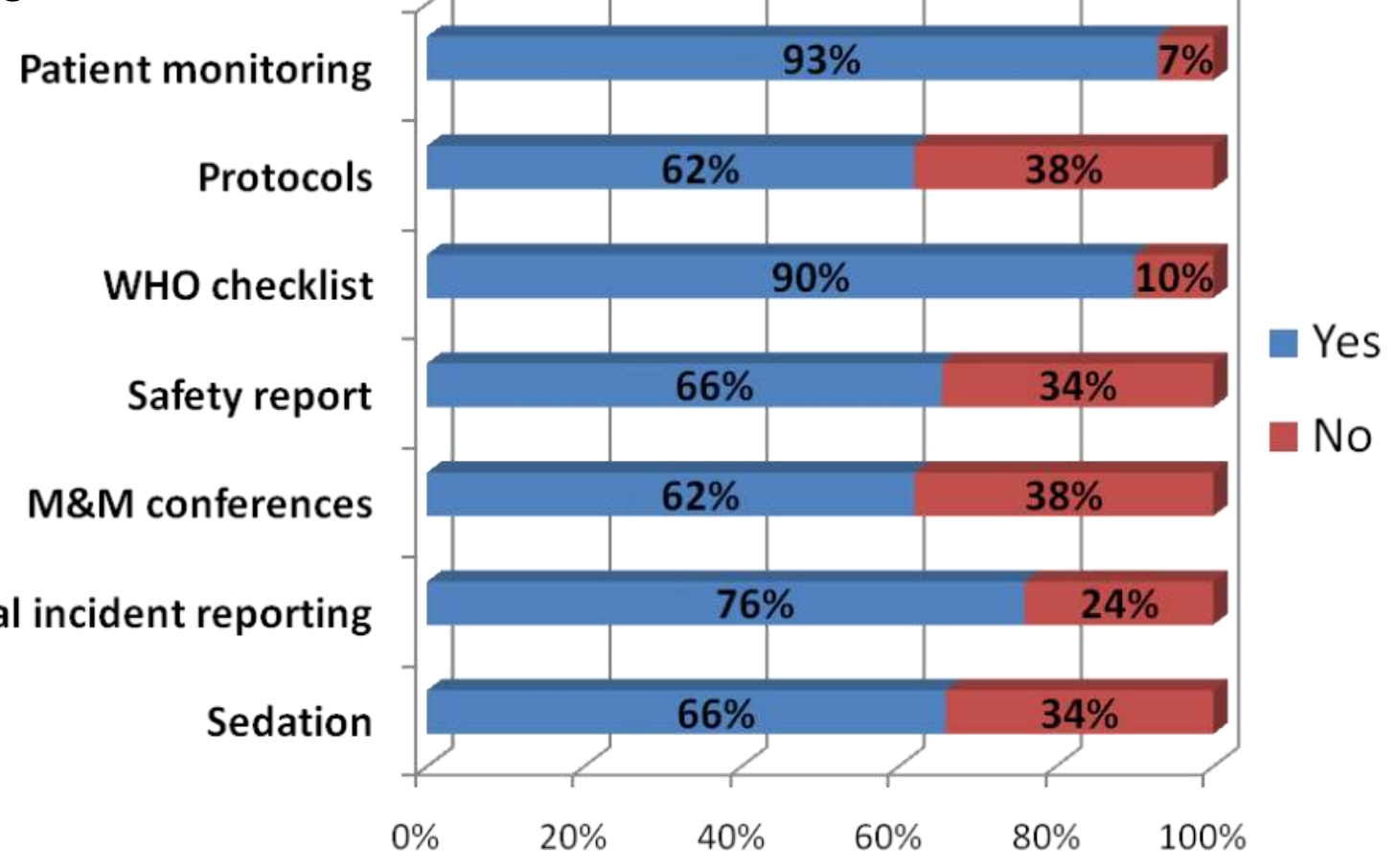

Fig.1 Percentage of safety measures fully established according to the Helsinki Declaration within Hospitals in Catalonia. Data from N: 29 Hospitals.

\begin{tabular}{|c|c|c|}
\hline Questions & $\%$ of affirmative answers & $\mathbf{N}^{0}$ \\
\hline $\begin{array}{l}\text { 1.Does your hospital have a recovery room? } \\
\text { Yes, } 24 \mathrm{~h} \text { per day } \\
\text { Yes, but only at core times } \\
\text { No }\end{array}$ & $\begin{array}{l}51.72 \% \\
44.83 \% \\
3.45 \%\end{array}$ & $\begin{array}{l}15 \\
13 \\
1\end{array}$ \\
\hline $\begin{array}{l}\text { 2. What kind of patient monitoring do you use in the OR / } \\
\text { recovery room? } \\
\text { ECG } \\
\text { Blood pressure } \\
\text { Pulse oximetry } \\
\text { Capnometry }\end{array}$ & \begin{tabular}{|l|}
$100 \%$ \\
$100 \%$ \\
$100 \%$ \\
$93.1 \%$
\end{tabular} & $\begin{array}{l}29 \\
29 \\
29 \\
27\end{array}$ \\
\hline $\begin{array}{l}\text { 3. Does your Hospital have the following protocols? } \\
\text {-Checking equipment and drugs } \\
\text {-Preoperative assessment and preparation } \\
\text {-Labeling of syringes } \\
\text {-Difficult/failed intubation } \\
\text {-Malignant Hiperthermia } \\
\text {-Anaphylaxis } \\
\text {-Local anesthetic toxicity } \\
\text {-Massive bleeding } \\
\text {-Infection Control } \\
\text {-Postoperative care, including pain relief }\end{array}$ & \begin{tabular}{|l|}
$96.55 \%$ \\
$96.55 \%$ \\
$89.66 \%$ \\
$100 \%$ \\
$79.31 \%$ \\
$93.10 \%$ \\
$89.66 \%$ \\
$86.21 \%$ \\
$96.55 \%$ \\
$96.55 \%$
\end{tabular} & $\begin{array}{l}28 \\
28 \\
26 \\
29 \\
23 \\
27 \\
26 \\
25 \\
28 \\
28\end{array}$ \\
\hline $\begin{array}{l}\text { 4. Do you use recognized sedation guidelines in your } \\
\text { hospital? }\end{array}$ & $65.52 \%$ & 19 \\
\hline $\begin{array}{l}\text { 5. Does your Hospital support the WHO Safe Surgery Saves } \\
\text { Lives Initiative and checklists? } \\
\text { Yes, in its original } \\
\text { Yes, in a modified version } \\
\text { No }\end{array}$ & $\begin{array}{l}17.24 \% \\
72.41 \% \\
10.34 \%\end{array}$ & \begin{tabular}{|l}
5 \\
21 \\
3
\end{tabular} \\
\hline $\begin{array}{l}\text { 6. Does your hospital gives an annual safety report? } \\
\text { In those who have responded yes, } \\
\text { What does it contain? } \\
\text { Measures taken } \\
\text { Results Obtained } \\
\text { Safety problems } \\
\end{array}$ & $\begin{array}{l}65.52 \% \\
94.74 \% \\
89.47 \% \\
78.95 \% \\
\end{array}$ & $\begin{array}{l}19 \\
19 \\
17 \\
15\end{array}$ \\
\hline $\begin{array}{l}\text { 7. Does your hospital hold conferences on patient } \\
\text { morbidity and mortality on a regular basis? } \\
\text { In those who have responded yes: } \\
\text { Are results published in an annual report? } \\
\text { Are improvement measures discussed? } \\
\text { Are there feedback mechanisms? }\end{array}$ & $\begin{array}{l}62.07 \% \\
82.35 \% \\
94.12 \% \\
88.24 \% \\
\end{array}$ & $\begin{array}{l}18 \\
14 \\
16 \\
15 \\
\end{array}$ \\
\hline $\begin{array}{l}\text { 8. Does your hospital provide a Critical Incident Reporting } \\
\text { System (CIRS)? } \\
\text { In those who have responded yes: } \\
\text { Are results published in an annual report? } \\
\text { Does your hospital contribute to CIRS? }\end{array}$ & $\begin{array}{l}75.86 \% \\
62.22 \% \\
73.91 \% \\
\end{array}$ & $\begin{array}{l}22 \\
15 \\
17\end{array}$ \\
\hline $\begin{array}{l}\text { 9. Does your hospital take part in a peer-review process or } \\
\text { has it participated in another form of accreditation? }\end{array}$ & $55.17 \%$ & 16 \\
\hline $\begin{array}{l}\text { 10. Does your hospital established its own quality } \\
\text { management system? }\end{array}$ & $48.28 \%$ & 14 \\
\hline
\end{tabular}

Table 1 Questionnaire and results

Data from $N$ : 29 hospitals

\section{Conclusions:}

Our results showed that most of the safety standards recommended in the HD were already applied in Catalan hospitals.

We conclude that the tertiary hospitals had a higher percentage of compliance than secondary hospitals in 6 of the 7 main items. Secondary hospitals were better in the compliance of the WHO checklist. The university hospitals had better scores in all the items of the survey.

Public institutions had greater compliance of the HD in 4 of the 7 main items, private institutions just were better in critical incident reporting, patient monitoring and morbidity/mortality sessions.

The two items that presented the lowest degree of compliance were morbidity/mortality sessions and the existence of recommended protocols. It is especially recommended in public hospitals to improve morbidity/mortality sessions which is the one with the lowest compliance.

\section{References:}

1. De Vries EN, Ramrattan MA, Smorenburg SM, et al. The incidence and nature of inhospital adverse events: a systematic review. Qual Saf Healthcare 2008; 3:216-223.

2. Mellin-Olsen J, Staender S, Whitaker DK, Smith AF. The Helsinki Declaration on Patient Safety in Anaesthesiology. Eur J Anaesthesiol 2010; 7:592-597. 